\title{
OPHTHALMIC Ophthalmic Genetics
}

\section{Neuro-ophthalmologic findings in humans with quadrupedal locomotion}

\section{Ozge Sarac, Suleyman Gulsuner, Yelda Yildiz-Tasci, Tayfun Ozcelik \& Tulay Kansu}

To cite this article: Ozge Sarac, Suleyman Gulsuner, Yelda Yildiz-Tasci, Tayfun Ozcelik \& Tulay Kansu (2012) Neuro-ophthalmologic findings in humans with quadrupedal locomotion, Ophthalmic Genetics, 33:4, 249-252, DOI: 10.3109/13816810.2012.689412

To link to this article: http://dx.doi.org/10.3109/13816810.2012.689412

册Published online: 11 Jun 2012.

Submit your article to this journal $\pi$

Џلll Article views: 138

Q View related articles $\widetilde{ }$

Citing articles: 6 View citing articles 다 


\title{
Neuro-ophthalmologic findings in humans with quadrupedal locomotion
}

\author{
Ozge Sarac ${ }^{1}$, Suleyman Gulsuner ${ }^{2}$, Yelda Yildiz-Tasci ${ }^{1}$, Tayfun Ozcelik ${ }^{3}$, and Tulay Kansu ${ }^{4}$ \\ ${ }^{1}$ Department of 2nd Ophthalmology, Ankara Ataturk Training and Research Hospital, Bilkent, Ankara, Turkey, \\ ${ }^{2}$ Department of Molecular Biology and Genetics, Faculty of Science, Bilkent University, Bilkent, Ankara, Turkey, \\ ${ }^{3}$ Institute of Materials Science and Nanotechnology, Bilkent University, Bilkent, Ankara, Turkey, and \\ ${ }^{4}$ Department of Neurology, Faculty of Medicine, Hacettepe University, Ankara, Turkey
}

\begin{abstract}
Purpose: To report the neuro-ophthalmologic findings in four patients from the same family with cerebellar ataxia, mental retardation, and dysequilibrium syndrome (CAMRQ)2 associated with quadrupedal locomotion. Method: A case series.

Results: All four patients carry the private missense mutation, WDR81 p.P856L. The brain Magnetic Resonance Imaging (MRI) of these patients revealed morphological abnormalities including mild hypoplasia of the corpus callosum, and atrophy of superior, middle, and inferior peduncles of the cerebellum. All patients had down-beat nystagmus, while two male patients additionally had bilateral temporal disc pallor along with ring-shaped macular atrophy.

Conclusions: The neuro-ophthalmic examination in CAMRQ2 revealed downbeat nystagmus in all patients, and temporal disc pallor and macular atrophy in two patients. It remains to be determined whether these findings are consistent in other forms of CAMRQ with mutations in VLDLR or CA8.
\end{abstract}

KEYWORDS: Cerebellar ataxia, mental retardation, dysequilibrium syndrome (CAMRQ), quadrupedal locomotion, neuro-ophthalmologic findings

\section{INTRODUCTION}

Cerebellar ataxia, mental retardation, and dysequilibrium syndrome (CAMRQ) is a genetically heterogenous autosomal recessive disorder which was first described by Schurig in 1981. ${ }^{1}$ In 2005 Tan first described a group of patients with CAMRQ associated with quadrupedal gait. ${ }^{2}$ The CAMRQ is characterized by congenital onset of cerebellar ataxia, disturbed equilibrium, and mental retardation, associated with cerebellar hypoplasia. Three different genes including the VLDLR gene encoding the very low density lipoprotein receptor (CAMRQ1 - MIM 224050), WDR81 gene encoding WD repeat domain 81 (CAMRQ2 - MIM 610185), and CA8 gene encoding carbonic anhydrase VIII (CAMRQ3 - MIM 613227) have been identified to harbor the causative mutations that lead to the phenotype of the CAMRQ. ${ }^{2-5}$
The quadrupedal gait is walking on all four extremities which occurs as a developmental regression with absence of the higher control mechanisms for asymmetric lateral balance during bipedal walking (Fig. 1). ${ }^{2}$ The subjects with quadrupedal gait preferred quadrupedal walking because of the difficulties maintaining a dynamic-asymmetric lateral balance and initiation of the first step during standing. They begin to move by crawling at the end of their first year but never learn to walk bipedally. They are able to stand upright without a support. However when they try to walk upright, they exhibit strong ataxia and return to the palmigrade walking position.

In this report, we present the neuro-ophthalmologic findings of four patients from the same family with CAMRQ2, of whom three were quadrupedal and one was bipedal. These patients carry the private missense mutation, WDR81 p.P856L. ${ }^{5}$

Received 04 February 2012; revised 26 March 2012; accepted 08 April 2012

Correspondence: Ozge Sarac, MD, Meksika Caddesi, Defne sitesi, 2. blok, Daire no:3, Umitkoy, Ankara, Turkey. Tel: +90 5057410018. Fax: +90 312 2912705. E-mail: osarac2002@yahoo.com 
All patients underwent complete neurologic and ophthalmologic examination including visual acuity, color vision, pupillary light reflex, slit-lamp, ocular motility and dilated fundoscopic examinations. To our knowledge the current report is the first one presenting the neuro-ophthalmologic findings in the CAMRQ2.

\section{CASES}

\section{Case I}

A 34-year-old male had quadrupedal gait (Fig. 1), severe mental retardation, and ataxia. His visual acuity and color vision were not possible to check because of the lack of cooperation. Pupils were equal, round, and reactive to light without evidence of relative afferent pupillary defect. Slit-lamp examination revealed normal findings for both eyes except some anterior peripheral cortical opacities in the left lens. The eye movements were full in all positions of gaze. A downbeat nystagmus was observed in primary gaze and persisted in all other positions of the gaze. The dilated fundoscopic examination revealed bilateral temporal disc pallor along with ring-shaped macular atrophy.

\section{Case 2}

A 30-year-old female had quadrupedal gait, mental retardation, ataxia, dysmetria, and intention tremor. The visual acuity for both eyes was counting fingers

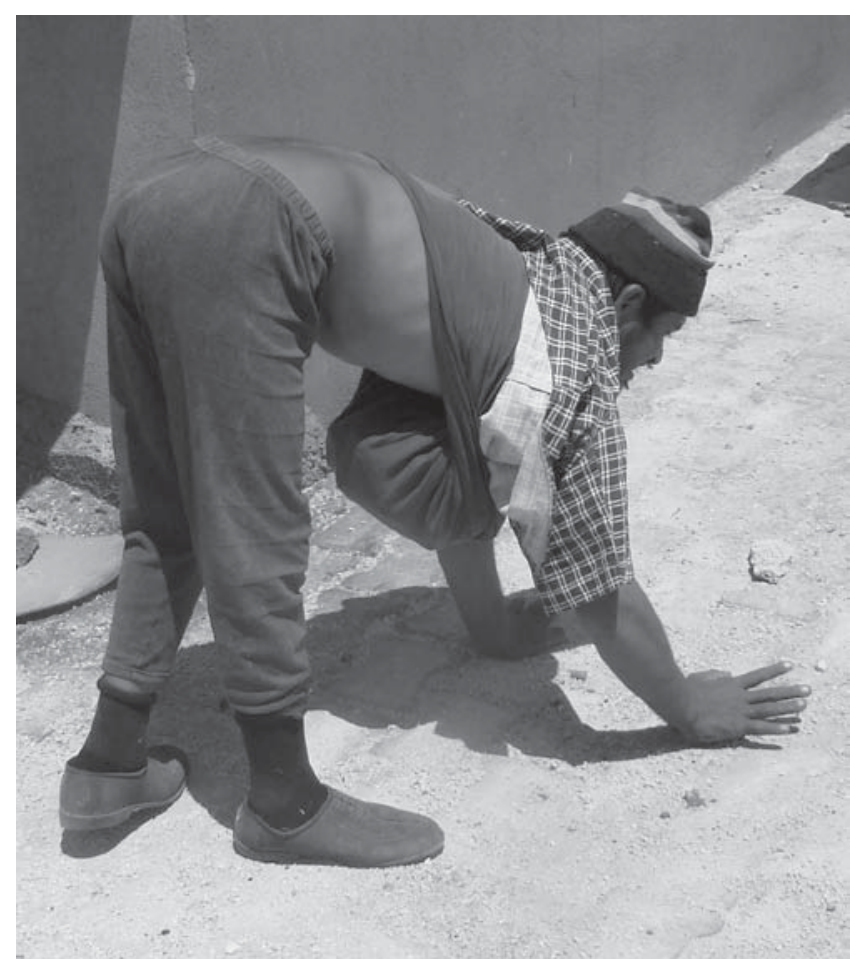

FIGURE 1 The quadrupedal gait of case 1. from 3 meters. The Snellen acuity chart could not be used to evaluate vision because of the poor compliance of the patient. Color vision was not able to checked. Pupils were equal, round, and reactive to light with no evidence of relative afferent pupillary defect. Biomicroscopic examination revealed no abnormality in both eyes. She had full ductions in all positions of gaze. A downbeat nystagmus in the primary position and downgaze which increased in velocity on gazes to the left and right was present. The dilated fundoscopic examination revealed normal findings in both eyes.

\section{Case 3}

A 40-year-old male had bipedal ataxic gait, mental retardation, bilateral sensorineural hearing loss, mild dysmetria, and intentional tremor. The visual acuity for both eyes was counting fingers from 3 meters. The Snellen chart could not be used to evaluate the visual acuity and color vision could not be tested because of the poor compliance of the patient. Pupils were equal, round, and reactive to light without evidence of relative afferent pupillary defect. Biomicroscopic examination revealed normal for both eyes. The eyes had full ductions. A downbeat nystagmus in the primary position which increased in velocity on downward gaze was detected. Similar to case 1, dilated fundoscopic examination revealed bilateral temporal disc pallor along with ring-shaped macular atrophy (Fig. 2).

\section{Case 4}

A 24-year-old female had quadrupedal gait and mental retardation. The visual acuity and color vision could not be examined because of her poor cooperation. Pupils were equal, round, and reactive to light with no evidence of relative afferent pupillary defect. Biomicroscopic examination was normal. There was no limitation of eye movements. A downbeat nystagmus was present in the primary position and persisted in right, left, and upgaze positions, but not in downgaze.

The dilated fundoscopic examination revealed no abnormality.

Table 1 summarizes the demographic findings, the gene mapping, brain magnetic resonance imaging (MRI) abnormalities, and major neurologic and ophthalmologic findings of all four cases.

\section{DISCUSSION}

Quadrupedal palm-gait with cerebellar and vermian hypoplasia and limited cognitive abilities in humans was first reported in $2005,{ }^{2}$ and since then it has been documented in a number of families from around the 

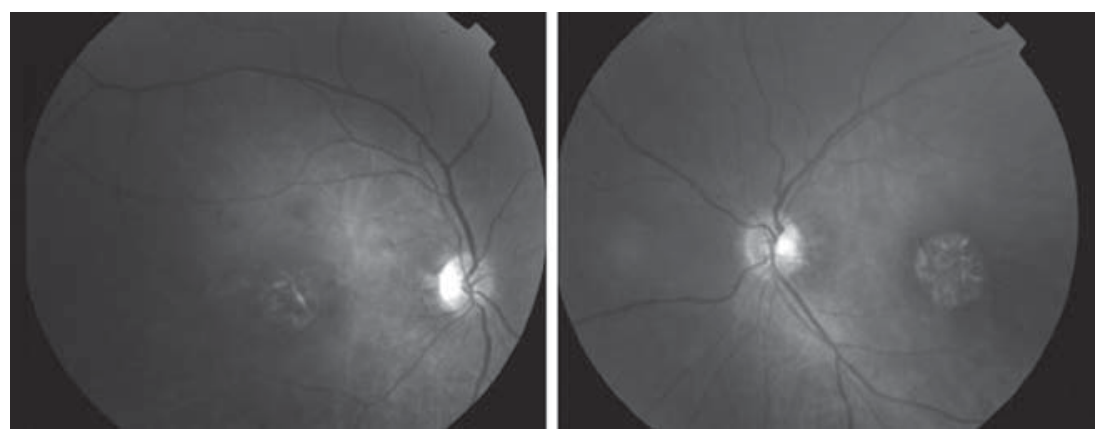

FIGURE 2 Bilateral temporal disc pallor and ring-shaped macular atrophy, and bilateral intorsion of the globes seen in case 3.

TABLE 1 The demographic findings, the gene mapping, brain magnetic resonance imaging (MRI), and major neurologic and ophthalmologic findings of all four cases.

\begin{tabular}{|c|c|c|c|c|c|c|}
\hline $\begin{array}{l}\text { Case } \\
\text { number }\end{array}$ & Gender & $\begin{array}{c}\text { Age } \\
\text { (years) }\end{array}$ & Gene mapping & Neurologic findings & Ocular findings & Brain MRI findings \\
\hline$\overline{1}$ & Male & 34 & $\begin{array}{l}\text { WDR81 p.P856L } \\
\text { on chromosome } \\
\text { 17p13.1-13.3 }\end{array}$ & $\begin{array}{l}\text { Severe mental retardation, } \\
\text { unable to talk, quadrupedal } \\
\text { gait, severe ataxia }\end{array}$ & $\begin{array}{l}\text { Downbeat nystagmus, bilateral } \\
\text { temporal disc pallor, bilateral } \\
\text { ring shaped macular atrophy } \\
\text { anterior peripheral cortical } \\
\text { opacities in the left lens }\end{array}$ & $\begin{array}{l}\text { Atrophy of the superior, } \\
\text { middle, and infe- } \\
\text { rior peduncles of the } \\
\text { cerebellum }\end{array}$ \\
\hline 2 & Female & 30 & $\begin{array}{l}\text { WDR81 p.P856L } \\
\text { on chromosome } \\
\text { 17p13.1-13.3 }\end{array}$ & $\begin{array}{l}\text { Mental retardation, can com- } \\
\text { municate only with her sister, } \\
\text { quadrupedal gait, ataxia, } \\
\text { dysmetria, intention tremor }\end{array}$ & Downbeat nystagmus & $\begin{array}{l}\text { Atrophy of the superior, } \\
\text { middle, and infe- } \\
\text { rior peduncles of the } \\
\text { cerebellum }\end{array}$ \\
\hline 3 & Male & 40 & $\begin{array}{l}\text { WDR81 p.P856L } \\
\text { on chromosome } \\
\text { 17p13.1-13.3 }\end{array}$ & $\begin{array}{l}\text { Mental retardation, able to } \\
\text { talk, bilateral sensorineural } \\
\text { hearing loss, bipedal, ataxic } \\
\text { gait, mild dysmetria, inten- } \\
\text { tional tremor }\end{array}$ & $\begin{array}{l}\text { Downbeat nystagmus, bilateral } \\
\text { temporal disc pallor, bilateral } \\
\text { ring shaped macular atrophy }\end{array}$ & $\begin{array}{l}\text { Atrophy of the superior, } \\
\text { middle, and infe- } \\
\text { rior peduncles of the } \\
\text { cerebellum }\end{array}$ \\
\hline 4 & Female & 24 & $\begin{array}{l}\text { WDR81 p.P856L } \\
\text { on chromosome } \\
\text { 17p13.1-13.3 }\end{array}$ & $\begin{array}{l}\text { Mental retardation, can com- } \\
\text { municate only with her sister, } \\
\text { quadrupedal gait, not coop- } \\
\text { erative for finger to nose test }\end{array}$ & Downbeat nystagmus & $\begin{array}{l}\text { Atrophy of the superior, } \\
\text { middle, and infe- } \\
\text { rior peduncles of the } \\
\text { cerebellum }\end{array}$ \\
\hline
\end{tabular}

world. Severe mental retardation, low-level conscious experience, speech disturbance, truncal ataxia with or without quadrupedal locomotion are observed in the affected individuals. ${ }^{1-7}$

In this report we investigated the neuro-ophthalmic findings of four patients from the same family with CAMRQ2 that harbour the WDR81 p.P856L mutation. The WDR81 gene on chromosome17p13.1-13.3 is predicted to encode for a transmembrane protein highly expressed in the cerebellum and corpus callosum, in particular in the Purkinje cell layer of the cerebellum. ${ }^{5}$ The function of this gene is not known and further studies should be done in order to reveal the mechanistic insights of cerebellar development and quadrupedal gait in humans.

The neuro-ophthalmic examination demonstrated that a down-beat nystagmus, an ocular motor sign typical for vestibulo-cerebellar lesions was present in all examined patients. Downbeat nystagmus is a vertical pursuit disorder and characterized by slow upward drifts and fast downward phases. ${ }^{8}$ The cerebellar nodulus and uvula play an important role in the control of the vertical pursuit. In cerebellar disease the downward pursuit is substantially reduced while the upward pursuit is relatively spared, causing an asymmetry in vertical pursuit. This asymmetry may lead to spontaneous upward drift that causes downbeat nystagmus. ${ }^{8,9}$ Downbeat nystagmus has been demonstrated in animals with cerebellar nodulus and uvula lesions. ${ }^{10}$ As previously reported, the neuroimaging techniques such as diffusion weighted imaging and fiber tractography of these reported patients' brains revealed morphological abnormalities in the cerebellum and corpus callosum, in particular atrophy of superior, middle, and inferior peduncles of the cerebellum. ${ }^{5}$ These findings explain the presence of the downbeat nystagmus in our patients.

The two male patients (Cases 1 and 3 ) had temporal disc pallor, and ring shaped macular chorioretinal atrophy, while females had normal fundus findings. Although case 1 was quadrupedal, and case 3 was bipedal they had the same optic disc and macular findings which may be specific manifestations of a kind of fundus dystrophia.

In conclusion, the neuro-ophthalmic examination in CAMRQ2 revealed downbeat nystagmus in all four patients, and temporal disc pallor and macular atrophy in two males. It needs to be confirmed whether these 
findings are consistent in other patients with the same disorder with mutations in VLDLR or CA8.

Declaration of interest: The authors report no conflicts of interest. The authors alone are responsible for the content and writing of the paper.

\section{REFERENCES}

1. Schurig V, Orman AV, Bowen P. Nonprogressive cerebellar disorder with mental retardation and autosomal recessive inheritance in Hutterites. Am J Med Genet 1981;9:43-53.

2. Tan U. Unertan syndrome; quadrupedality, primitive language, and severe mental retardation; a new theory on the evolution of human mind. NeuroQuantology 2005;4:250-255.

3. Ozcelik T, Akarsu N, Uz E, et al. Mutations in the very lowdensity lipoprotein receptor VLDLR cause cerebellar hypoplasia and quadrupedal locomotion in humans. Proc Natl Acad Sci USA 2008;105:4232-4236.

4. Türkmen S, Guo G, Garshasbi M, et al. CA8 mutations cause a novel syndrome characterized by ataxia and mild mental retardation with predisposition to quadrupedal gait. PLoS Genet 2009;5(5):e1000487.

5. Gulsuner S, Tekinay AB, Doerschner K, et al. Homozygosity mapping and targeted genomic sequencing reveal the gene responsible for cerebellar hypoplasia and quadrupedal locomotion in a consanguineous kindred. Genome Res 2011;21:1995-2003.

6. Tan U. Unertan syndrome: review and report of four new cases. Int J Neurosci 2008;118:211-225.

7. Tan U, Pençe S, Yilmaz M, et al. Unertan syndrome in two Turkish families in relation to devolution and emergence of Homo erectus: neurological examination, MRI, and PET scans. Int J Neurosci 2008;118:313-336.

8. Glasauer S, Hoshi M, Büttner U. Smooth pursuit in patients with downbeat nystagmus. Ann N Y Acad Sci 2005;1039:532-535.

9. Marti S, Bockisch CJ, Straumann D. Prolonged asymmetric smooth-pursuit stimulation leads to downbeat nystagmus in healthy human subjects. Invest Ophthalmol Vis Sci 2005;46:143-149.

10. Walker MF, Tian J, Shan X, Ying H, Tamargo RJ, Zee DS. Enhancement of the bias component of downbeat nystagmus after lesions of the nodulus and uvula. Ann N Y Acad Sci 2009;1164:482-485. 